\title{
A pheochromocytoma in a patient with neurofibromatosis type 1: A case report
}

\section{Faten Hadjkacem, Imen Gargouri, Mehdi Kalthoum, Mouna Elleuch, Nadia Charfi, Mohamed Abid}

Department of Endocrinology, Hedi Chaker University Hospital, Sfax, Tunisia

Corresponding author: Dr. Imen Gargouri, E-mail: imenegargouri1@gmail.com

\begin{abstract}
Neurofibromatosis type 1 is one of the most common autosomal dominant disorder characterized by an extreme variability of its manifestations even within the same family. It carries an increased risk of pheochromocytoma. Although rare, recent literature recommend routine screening for symptomatic patients with neurofibromatosis type 1. A 46-yearold man, normotensive, presented a right-adrenal incidentaloma and investigations revealed a pheochromocytoma. We remind the benefit of screening and earlier identification of this affection in patients with neurofibromatosis type 1 to prevent from the morbidity and mortality secondary to an excess of catecholamine secretion.
\end{abstract}

Key words: Neurofibromatosis type 1; Von Recklinghausen Disease; Pheochromocytoma; Hypertension

\section{INTRODUCTION}

Neurofibromatosis type $1(\mathrm{NFl})$ also known as Von Recklinghausen disease, is a common autosomal dominant disorder due to mutation or a deletion of the NFlgene located at $17 \mathrm{ql} 1.2$. Affected individuals are at a higher risk for pheochromocytoma and paraganglioma. Its prevalence in patients with hypertension is $0.2-0.6 \%$ but can reach $5.7 \%$ in patients with NF1 [1,2]. Recent literature suggests screening for pheochromocytoma (Pheo) in patients with NFl who develops hypertension or any symptom suggestive of pheochromocytoma and paraganglioma, due to its morbidity and mortality when undiagnosed or when the diagnosis is delayed [3].

We present a case with neurofibromatosis type 1 with an adrenal incidentaloma which turned to be a Pheo after biological investigations and imaging and we remind the benefit of earlier identification.

\section{CASE REPORT}

A 46 year-old male presented a progressive asthenia and weight loss (9kg weight loss in 4 years) neglected by the patient with a history of gastrointestinal haemorrhage twelve years ago. He was initially admitted in general surgery department for treatment of his bilio-enteric fistula secondary to a duodenal ulcer. An assessed CTscan showed two well-defined right adrenal masses measuring each $128 \times 87 \times 86 \mathrm{~mm}$ and $60 \times 52 \times 37 \mathrm{~mm}$ with central necrosis and calcifications in the biggest one. It suppresses the right kidney and fill in the vertebral foramens D12-L1 and L1-L2 without osteolyses. The magnetic resonance imaging(MRI) showed the same well-defined heterogeneous masses with intense enhancement without spread to adjacent organs (Fig. 1).

So he was referred to our department to explore these masses.

His family history was pertinent for NFl in his two sisters and two nephews.

He quit smoking for twenty years and he denied any medication, alcohol or drug use. He mentioned headache, palpitations, and sweating for four years without hypertension. His weight was $51 \mathrm{~kg}$ height 1,72 meters, body mass index was at $17,23 \mathrm{~kg} / \mathrm{m}^{2}$.

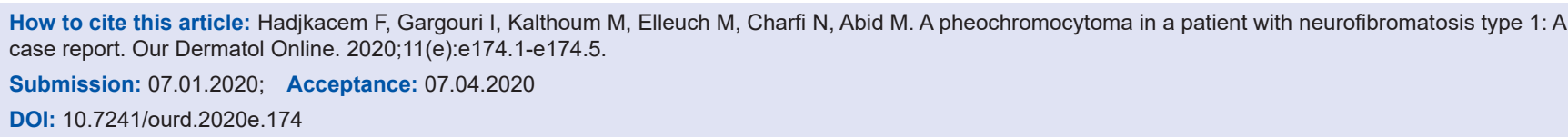


Vital signs were normal, blood pressure was 120/80 $\mathrm{mmHg}$ and hypertension was excluded after assessing a normal 24 hours-blood-pressure monitoring. Palpation of the thyroid gland did not find any nodule or abnormality. Physical exam found multiple caféau-lait macules, axillary inguinal and many cutaneous neurofibromas mostly in the trunk (Fig. 2).

A left-eye-redness was noticed and the presence of Lisch nodule in the left eye was confirmed after ophthalmological examination. No Skeletal abnormalities were noticed. X-ray on tibia and radius were normal. In initial pulmonary CT-scan, centrilobular and paraseptal emphysema, fibrosis and peripheral-apex micro nodules were noticed. Another CT-scan was assessed showed the same bilateral parenchymal lesions mainly in the apex evoking bronchiolitis.

A biochemical tests initiated for his adrenal incidentaloma showed increases in both norephrine

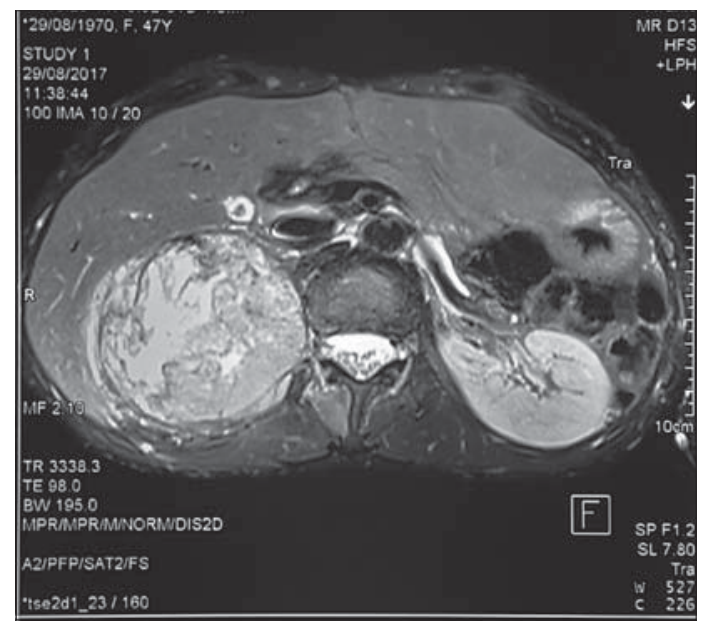

Figure 1: MRI showing the right adrenal masses.

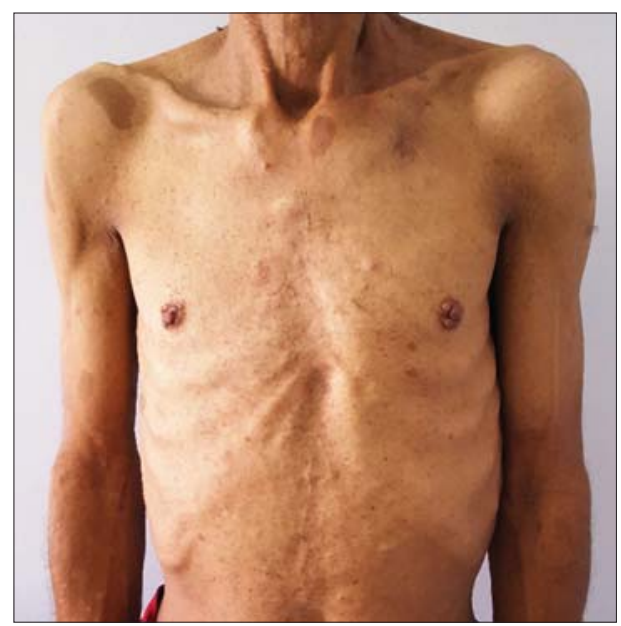

Figure 2: Cutaneous neurofibroma and café-au-lait patches of the trunk.
$6.3 \mathrm{nmol} / \mathrm{l}$ (normal $<0.92 \mathrm{nmol} / \mathrm{l})$ and epinephrine $3.15(<1.29 \mathrm{nmol} / \mathrm{l})$. Aldosterone was at $191.15 \mathrm{pg} / \mathrm{ml}$ and renin at $85.54 \mathrm{pg} / \mathrm{ml}$ suggestive of a secondary hyperaldosteronsim. Bedtime serum cortisol was abnormal and cortisol after lmg dexamethasone suppressive test was $12.7 \mathrm{ng} / \mathrm{ml}$.

11-desoxycortisol and 11-desoxycorticosterone were normal 0.6(0.2-1.1ng/ml) and 114(40-170 pg/ml) respectively.

Pheochromocytoma was highly suspected and functional imaging by ${ }^{131}$ I-metaiodobenzylguanidine showed only an intense uptake on the right side of the abdomen in the level of Ll super-imposed on the right adrenal gland in the CT. Adrenalectomy was indicated but the patient refused the surgery.

\section{DISCUSSION}

$\mathrm{NF}$ l is a common autosomal dominant disorder due to mutation or a deletion of the NFl gene, a tumour suppressor gene located at $17 \mathrm{ql} 1.2$ which codes for neurofibromin that is a GTPase-activating protein involved in the inhibition of renin-angotensin system. Neurofibromatosis can be diagnosed if two or more criteria are found according to National Institute of Health which are [4]:

1. Six or more cafe au lait macules over $5 \mathrm{~mm}$ in greatest diameter in prepubertal individuals and over $15 \mathrm{~mm}$ in greatest diameter in postpubertal individuals.

2. Two or more cutaneous/subcutaneous neurofibromas of any type or one plexiform neurofibroma.

3. Freckling in the axillary or inguinal regions.

4. Optic pathway glioma.

5. Two or more Lisch nodules (iris hamartomas seen on slit lamp examination).

6. Bone dysplasia such as sphenoid dysplasia or thinning of long bone cortex, with or without pseudarthrosis.

7. A first-degree relative (parent, sibling, or offspring) with NF-1.

In our case 5 criteria were fulfilled. The differential diagnoses of NFl include other forms of neurofibromatosis. One or two café-au-lait patches occur in $10 \%$ of the general population(5). And the lack of other criteria should suggest a follow up in a specialised center because it might be a mosaic form of $\mathrm{NF} 1$ or neurofibromatosis type2. In neurofibromatosis type 2 café-au-lait patches are less numerous and 
shwannomas occurs in vestibular, spinal cranial or peripheral nerves. Subcutaneous schwannomas can be confused with neurofibromas and biopsy can be necessary in some cases to distinguish neurofibromas from lipomas and schwannomas [5].

Neurofibromas can be cutaneous or subcutaneous, their number and size can increase in the adolescence or adulthood and can reach even thousands. When it impairs function or affect self-image, surgery is recommended. Spinal neurofibroma may develop in any level of the spinal cord and can compromise its function in addition of the risk of malignant transformation into malignant peripheral nerve sheath tumours (813\%) $[5,6]$. Batista et al. [6] proposed an algorithm for treatment of neurofibroma. This cancer has bad prognosis and that's why patients affected with NFl should be educated about unusual symptoms or those suggesting those complications. It seems to be more important than the periodic medical examination [7].

Pulmonary complications are often associated with NF1 and has been reported in few series. The prevalence of parenchymal lung disease in patients with NFl was 7 to $23 \%[8,9]$. Several manifestations were described in the literature such as interstitial fibrosis, obstructive neurofibromas, infiltrative lesions, cysts, bubbles (50\%), emphysema $(25 \%)$ or bibasilar reticulations (50\%) [10]. Even pulmonary hypertension has been described which can be due to parenchymal lesions or the involvement of pulmonary arteries. CT-scan shows Emphysema, scattered cystic spaces, peripheral groundglass and reticular densities, ground-glass opacities [11]. Emphysema and interstitial fibrosis are two different disorders, their association can occur more importantly in smoking-patients[10], even though it remains controversial in some studies [9]. Our patient was a tobacco user had no symptoms and his thoracic CTscan showed a bilateral-upper-paraseptal emphysema, peripheral nodules suggestive of bronchiolitis with reticular densities and linear fibrosis.

As for gastro-intestinal manifestations, described in $25 \%$ of patients with NF1 $[14,15]$, they can be the first manifestation of the disease. The clinical, radiographic and histological findings are not specific to NFl. The most common symptoms are diarrhoea or constipation, abdominal pain, intestinal obstruction and palpable abdominal masses but also dyspepsia and haemorrhage who can be related to intestinal neurofibroma. Gastrointestinal tumours were found in one-third of autopsy series of patients with NFl [16]. Gastrointestinal stromal tumours are the most common mesenchymal tumours of the gastrointestinal system [5]. The manifestations can be only anaemia and bleeding. Our patient presented a gastro-intestinal bleeding with anaemia but no images suggestive of intestinal tumours were seen in the CT.

The prevalence of Pheo in patients with NFl is more important in patients with hypertension in general population, $1.0 \%-5.7 \%$ versus $0.2-0.6 \%$ and even higher rates are in those with NFl and hypertension at 20\%-50\% [1,9-22]. Two prospective studies showed higher prevalence of Pheo in which patients with NF1 were screened for Pheo (7.7\% [3] and 14.6\% [22]). It can be explained by the fact that routine screening for PPGLS is not recommended by the guidelines in normotensive or asymptomatic patients [20].

Pheo in NF-1 can be entirely asymptomatic suggesting that its true prevalence is unknown but clinicians should not ignore the possibility of the presence of Pheo in the lack of hypertension. The commonest clinical signs besides the hypertension includes, palpitations, headache, dizziness or sweating were found in more than half patients in Gruber et al. study [20]. NFl patients should undergo screening for this affections especially when associated with catecholamine-symptoms or hypertension [25]. The mean age at the moment of diagnosis was reported between the age of fourty and fifty in some studies $[19,20]$.

In patients with NF1, Pheo usually produces epinephrine and norepinephrine $[21,23,24]$. The best diagnostic test is serum metanephrines and diagnosis is established if plasma metanephrines are increased [9,21]. Our patient, aged 46, presented paroxysmal symptoms such as palpitations, wetting and headache without hypertension and the biochemical assessment confirmed the catecholamine secretion of epinephrine and norepinephrine.

An adrenal mass can be discovered accidentally in patients with NF1, and must be evaluated to exclude Pheo. Those masses can be mistaken for non-functional gonglioneuroma or a gastrointestinal mass in CT-scan and biopsy could be fatal [25]. In most cases it is unilateral intra-adrenal mass, bilateral or multifocal in $10 \%$ to $15 \%$ of patients $[21,23]$ and can be also extraadrenal in 0-6\% [23].

Malignancy occurs in 3 to $12 \%[20,25]$. Myrick et al. reported that the size of adrenal tumours in NFl patients 
is almost half the size of patients non-NF1 [28]. But our patient had huge masses similar to non-NFl patients.

Treatment in patients with Peo associated with NF1 seems to be similar in patients without NFl [28]. Surgical removal is the effective treatment [21].

Currently, studies did not establish a genetic-clinical association between NFl and Pheo due to the variability of the expression of this disease, the large size of the gene, the lack of hot spots and the high rate of de novo mutations $[19,25]$. But some studies reported that loss of heterozygosity was observed in Pheo associated with $\mathrm{NFl}$ and it seems to be that Pheo is considered as a true component of NF1 [26].

\section{CONCLUSION}

To summarize, annual examination and screening for $\mathrm{NFl}$ in adulthood include blood pressure measurement, ophthalmological exam, physical exam for the skin and the skeleton and other tests or imaging according to the symptoms reported by the patients. Screening for PPGLs is recommended for symptomatic or hypertensive patients but others support a routine screening regardless of the age or the symptoms [20]. This affection can be potentially malignant [17] and increase the morbidity and mortality secondary to catecholamine secretion when the diagnosis is delayed. Special health care and education should be provided to those patients.

\section{Consent}

The examination of the patient was conducted according to the Declaration of Helsinki principles.

The authors certify that they have obtained all appropriate patient consent forms. In the form the patient(s) has/have given his/her/ their consent for his/her/their images and other clinical information to be reported in the journal. The patients understand that their names and initials will not be published and due efforts will be made to conceal their identity, but anonymity cannot be guaranteed.

\section{REFERENCES}

1. Tate JM, Gyorffy JB, Colburn JA. The importance of pheochromocytoma case detection in patients with neurofibromatosis type 1: A case report and review of literature. SAGE Open Med Case Reports. 2017;5:2050313X1774101.

2. Petrovska J, Kitanovska BG, Bogdanovska S, Kuzmanoska SP. Pheochromocytoma and Neurofibromatosis Type 1 in a Patient with Hypertension. Open access Maced J Med Sci. 2015;3:713-6.

3. Képénékian L, Mognetti T, Lifante J-C, Giraudet A-L, Houzard C, Pinson S, et al. Interest of systematic screening of pheochromocytoma in patients with neurofibromatosis type 1. Eur J Endocrinol. 2016;175:335-44.

4. National Institutes of Health Consensus Development Conference Statement: neurofibromatosis. Bethesda, Md., USA, July 13-15, 1987. Neurofibromatosis. 2018;1:172-8.

5. Ferner RE, Huson SM, Thomas N, Moss C, Willshaw H, Evans DG, et al. Guidelines for the diagnosis and management of individuals with neurofibromatosis 1. J Med Genet. 2007;44:81-8.

6. Batista PB, Bertollo EMG, Costa D de S, Eliam L, Cunha KSG, Cunha-Melo JR, et al. Neurofibromatosis: part 2 - clinical management. Arq Neuropsiquiatr. 2015;73:531-43.

7. Van Lierde A, Menni F, Bedeschi MF, Natacci F, Guez S, Vizziello P, et al. Healthcare transition in patients with rare genetic disorders with and without developmental disability: neurofibromatosis 1 and Williams-Beuren syndrome. Am J Med Genet. 2013;161A:1666-74.

8. Malviya A, Mishra S, Kothari SS. Type 1 neurofibromatosis and pulmonary hypertension: a report of two cases and a review. Heart Asia. 2012;4:27-30.

9. Shino M, Rabbani S, Belperio J, Lynch J, Weigt S. NeurofibromatosisAssociated Diffuse Lung Disease: Case Report. Semin Respir Crit Care Med. 2012;33:572-6.

10. Zamora AC, Collard HR, Wolters PJ, Webb WR, King TE. Neurofibromatosis-associated lung disease: a case series and literature review. Eur Respir J. 2007;29:210-4.

11. Ferreira S, Júnior A, Zanetti G, Severo A, Melo A De, Soares A, et al. Neuro fi bromatosis type 1 : State-of-the-art review with emphasis on pulmonary involvement. Respir Med. 2019;149:9-15.

12. Miyamoto K. Pulmonary manifestations in von Recklinghausen's disease. Intern Med. 1997;36:381.

13. Ryu JH, Parambil JG, McGrann PS, Aughenbaugh GL. Lack of evidence for an association between neurofibromatosis and pulmonary fibrosis. Chest. 2005;128:2381-6.

14. Fernandes A, Ferreira AM, Serra P, Carvalho L. Intestinal ganglioneuromatosis: An unusual aetiology for occult gastrointestinal bleeding. BMJ Case Rep. 2015;2015:1-5.

15. Yamamoto R, Kato S, Maru T, Ninomiya R, Ozawa F, Beck Y, et al. The Coexistence of Somatostatinoma and Gastrointestinal Stromal Tumor in the Duodenum of a Patient with Von Recklinghausen's Disease. Intern Med. 2016;55:617-22.

16. Hurley RH, McCormick M, Elhassan M, Nicholson G. Gastrointestinal stromal tumour as a rare association with neurofibromatosis type 1. J Surg Cas Rep. 2018;2018:rjy017.

17. Walther MM, Herring J, Enquist E, Keiser HR, Linehan WM. von Recklinghausen's disease and pheochromocytomas. J Urol [Internet]. 1999;162:1582-6.

18. Seo Y, Jeong Y, Kim DY, Choi K, Kim ES, Moon SD, et al. A novel neurofibromatosis type 1 (NF1) mutation in a patient with nf1 and pheochromocytoma. Korean J Intern Med. 2018;33:214-7.

19. Wong C-L, Fok C-K, Tam VH-K. Concurrent primary hyperparathyroidism and pheochromocytoma in a Chinese lady with neurofibromatosis type 1 . Endocrinol diabetes Metab Cas Rep. 2018;2018.

20. Gruber LM, Erickson D, Babovic-Vuksanovic D, Thompson GB, Young WF, Bancos I. Pheochromocytoma and paraganglioma in patients with neurofibromatosis type 1. Clin Endocrinol (Oxf). 2017;86:141-9.

21. Vlenterie M, Flucke U, Hofbauer LC, Timmers HJLM, Gastmeier J, Aust DE, et al. Pheochromocytoma and gastrointestinal stromal tumors in patients with neurofibromatosis type I. Am J Med. 2013;126:174-80.

22. Zinnamosca L, Petramala L, Cotesta D, Marinelli C, Schina M, Cianci R, et al. Neurofibromatosis type 1 (NF1) and pheochromocytoma: prevalence, clinical and cardiovascular aspects. Arch Dermatol Res. 2011;303:317-25.

23. Mazzaglia PJ. Hereditary pheochromocytoma and paraganglioma. J Surg Oncol. 2012;106:580-5.

24. Eisenhofer G, Lenders JWM, Timmers H, Mannelli M, Grebe SK, 


\section{www.odermatol.com}

Hofbauer LC, et al. Measurements of plasma methoxytyramine, normetanephrine, and metanephrine as discriminators of different hereditary forms of pheochromocytoma. Clin Chem. 2011;57:41120.

25. Vanderveen KA, Thompson SM, Callstrom MR, Young WF, Grant CS, Farley DR, et al. Biopsy of pheochromocytomas and paragangliomas: potential for disaster. Surgery 2009;146:1158-66.

26. Bausch B, Borozdin W, Mautner VF, Hoffmann MM, Boehm D, Robledo M, et al. Germline NF1 mutational spectra and lossof-heterozygosity analyses in patients with pheochromocytoma and neurofibromatosis type 1. J Clin Endocrinol Metab. 2007;92:2784-92.
27. Farrugia FA, charalampopoulos A. Pheochromocytoma. Endocr Regul. 2019;53:191-212.

28. Shinall M, Solórzano C. Pheochromocytoma in neurofibromatosis type 1: When should it be suspected? Endocr Pract. 2014;20:792-6.

Copyright by Faten Hadjkacem, et al. This is an open access article distributed under the terms of the Creative Commons Attribution License, which permits unrestricted use, distribution, and reproduction in any medium, provided the original author and source are credited.

Source of Support: Nil, Conflict of Interest: None declared. 